\title{
Valor nutritivo de pastagens de Coastcross- 1 em consórcio com diferentes leguminosas de ciclo hibernal
}

\author{
[Nutritive value of coastcross-1 pastures mixed to different cool season legumes] \\ P.F. Aguirre ${ }^{1}$, C.J. Olivo ${ }^{2}$, G.D. Smonetti ${ }^{3}$, C.A. Agnolin ${ }^{2}$, J.S. Nunes ${ }^{3}$, C.M. De Bem ${ }^{1}$, \\ M.S. Diehl ${ }^{1}$, C.P. Sauter ${ }^{3}$, P.R. Fernandes ${ }^{3}$ \\ ${ }^{1}$ Aluna de pós-graduação - Universidade Federal de Santa Maria - Santa Maria, RS \\ ${ }^{2}$ Universidade Federal de Santa Maria - Santa Maria, RS \\ ${ }^{3}$ Aluna de graduação - Universidade Federal de Santa Maria - Santa Maria, RS
}

\begin{abstract}
RESUMO
Objetivou-se com esta pesquisa avaliar três sistemas forrageiros constituídos por Coastcross-1 (CC) + $100 \mathrm{~kg}$ de N/ha/ano + ervilhaca comum; CC $+100 \mathrm{~kg}$ de N/ha/ano + trevo vesiculoso; e CC $+200 \mathrm{~kg}$ de $\mathrm{N} /$ ha/ano. Durante o período experimental (345 dias), foram realizados treze pastejos. O delineamento experimental utilizado foi o inteiramente ao acaso, com três tratamentos (sistemas forrageiros), três repetições (piquetes) em parcelas subdividas no tempo (valores médios dos pastejos em cada estação do ano). Para avaliação, foram utilizadas vacas em lactação da raça Holandesa. Amostras de simulação de pastejo foram coletadas para análise de proteína bruta (PB), fibra em detergente neutro (FDN) e ácido (FDA), digestibilidade in situ da matéria seca (DISMS) e da matéria orgânica (DISMO) e os nutrientes digestíveis totais (NDT). Os valores médios para PB, FDN, FDA, DISMS, DISMO e NDT foram de 18,1; 16,7 e $17,6 \% ; 57,8 ; 58,9$ e $58,7 \% ; 26,5 ; 26,5$ e $26,7 \% ; 79,6 ; 78,9$ e $80,6 \% ; 79,8 ; 79,1$ e $80,6 \% ; 72,1 ; 71,4$ e $72,7 \%$, respectivamente. Melhores resultados de valor nutritivo foram obtidos no inverno, em especial para o consórcio de Coastcross-1 com ervilhaca.
\end{abstract}

Palavras-chave: Cynodon dactylon, Trifolium vesiculosum, vacas em lactação, Vicia sativa

\begin{abstract}
The aim of this research was to evaluate three grazing systems with Coastcross-1 (CC) $+100 \mathrm{~kg}$ N/ha/year + common vetch; CC + 100kg N/ha/year + arrowleaf clover; and CC + 200kg N/ha/year. Thirteen grazing cycles were performed during the experimental period (345 days). The experimental design was completely randomized with three treatments (grazing systems), three replicates (paddocks) in completely split-plot time (average values of grazing season). Lactating Holstein cows were used in the evaluation. Forage mass and botanical composition were evaluated. Samples from the hand-plucking method were collected to analyze crude protein (CP), neutral detergent fiber (NDF) and acid (ADF), in situ digestibility of dry matter (ISDMD) and organic matter (ISOMD) and total digestible nutrients (TDN). The averages of CP, NDF, ADF, ISDMD, ISOMD and TDN were 18.1, 16.7 and $17.6 \%$; 57.8, 58.9 and $58.7 \%$; 26.5, 26.5 and 26.7\%; 79.6, 78.9 and $80.6 \%$; 79.8, 79.1 and $80.6 \%$; 72.1, 71.4 and $72.7 \%$, respectively. Better results for nutritive value were found during winter, especially on Coastcross-1 mixed with common vetch.
\end{abstract}

Keywords: Cynodon dactylon, lactating cows, Trifolium vesiculosum, Vicia sativa

\section{INTRODUÇÃO}

A pecuária de leite brasileira passa por um acelerado processo de modernização (Vilela et al., 2006); desse modo, as propriedades familiares do Sul do País, que representam a maior parcela dos produtores de leite da região, necessitam se adequar às exigências impostas pelo mercado, adequando-se a um modelo de produção mais sustentável.

Recebido em 4 de fevereiro de 2014

Aceito em 12 de março de 2015

E-mail: clairolivo@yahoo.com.br 
Nesse contexto, gramíneas do gênero Cynodon têm sido amplamente utilizadas na América tropical e subtropical, tanto para pastejo quanto para produção de feno (Branco et al., 2012), devido à sua alta produção de forragem por unidade de área, elevado valor nutricional e adaptação às condições de clima dessas regiões.

No entanto, variedades como Coastcross-1 e o Tifton 85 são exigentes em fertilidade do solo, sendo o nitrogênio um dos principais nutrientes necessários para o aumento da produtividade dessas gramíneas (Alvim e Botrel, 2001; Corrêa et al., 2007). O cultivo dessas forrageiras normalmente é feito de forma singular, implicando custos elevados de adubação nitrogenada. Para minimizar esses custos e tornar o ambiente pastoril mais sustentável, recomendase a introdução de leguminosas, que contribuem diversificando o sistema forrageiro, reduzindo os riscos de ocorrência de pragas, doenças e degradação das pastagens (Silva e Saliba, 2007). Apesar desse potencial, são raros os estudos de consórcio de gramíneas do gênero Cynodon com leguminosas forrageiras, especialmente sob condições de pastejo. Dentre as leguminosas destacam-se a ervilhaca (Vicia sativa L.) e o trevo vesiculoso (Trifolium vesiculosum Savi), devido ao fato de possuírem ciclos distintos das gramíneas desse gênero, diminuindo a competição por nutrientes e luz.

Dessa forma, objetivou-se com este trabalho avaliar o valor nutritivo e a massa de forragem de sistemas forrageiros compostos por Coastcross-1 e diferentes leguminosas de ciclo hibernal.

\section{MATERIAL E MÉTODOS}

A pesquisa foi conduzida em área do Laboratório de Bovinocultura de Leite, pertencente ao Departamento de Zootecnia da Universidade Federal de Santa Maria (RS), situada na Depressão Central do Rio Grande do Sul, de maio de 2012 a maio de 2013. O solo é classificado como Argissolo Vermelho distrófico arênico pertencente à unidade de mapeamento São Pedro (Streck et al., 2008) e, conforme os resultados da análise de solo, realizada em 2011, obtiveram-se os seguintes valores médios: $\mathrm{pH}-\mathrm{H} 2 \mathrm{O}=5,4$; índice SMP $=5,9 ;$ argila $=20 \%$; $\mathrm{P}=16,32 \mathrm{mg} / \mathrm{dm}^{3} ; \mathrm{K}=102 \mathrm{mg} / \mathrm{dm}^{3} ; \mathrm{MO}=$ $2,65 \% ; \mathrm{Al}=0,4 \mathrm{cmolc} / \mathrm{dm}^{3} ; \mathrm{Ca}=4,9 \mathrm{cmolc} / \mathrm{dm}^{3}$;
$\mathrm{Mg}=2,2 \mathrm{cmolc} / \mathrm{dm}^{3}$; saturação de bases $=58,6 \% \mathrm{e}$ saturação por $\mathrm{Al}=5,6 \%$. O clima da região é o subtropical úmido (Cfa), conforme classificação de Köppen (Moreno, 1961). Os dados meteorológicos foram obtidos na Estação Meteorológica da UFSM, situada a $500 \mathrm{~m}$ do local da área experimental, aproximadamente. Os valores de temperatura média mensal e precipitação pluviométrica referente ao período experimental, de maio de 2012 a maio de 2013 , foram de $19,3^{\circ} \mathrm{C}, 123,2 \mathrm{~mm} / \mathrm{mês}$; as médias das normais climatológicas para o respectivo período são de $19,5^{\circ} \mathrm{C}, 140,5 \mathrm{~mm} / \mathrm{mês}$. Foram registradas vinte geadas ao longo do período experimental, sendo seis em junho, doze em julho, uma em setembro de 2012 e uma em maio de 2013.

Para a avaliação experimental, foi utilizada uma área de $5.130 \mathrm{~m}^{2}$, subdividida em nove piquetes. Os tratamentos foram constituídos pelos seguintes sistemas forrageiros: capim bermuda (Cynodon dactylon L. Pers.), cv. Coastcross-1 + $100 \mathrm{~kg}$ de N/ha/ano + ervilhaca (Vicia sativa L.), cv. Comum; Coastcross- $1+100 \mathrm{~kg}$ de N/ha/ano + trevo vesiculoso (Trifolium vesiculosum Savi) cv. Yuchi; e Coastcross- $1+200 \mathrm{~kg}$ de N/ha/ano. A Coastcross-1 já havia sido implantada manualmente na área, utilizando-se mudas provenientes da subdivisão de touceiras. Em três piquetes, realizou-se no mês de maio a sobressemeadura da ervilhaca, mediante plantio direto, com densidade de $60 \mathrm{~kg} / \mathrm{ha}$, com espaçamento de $17 \mathrm{~cm}$ entre linhas. Em outros três piquetes, realizou-se também em maio a sobressemeadura do trevo vesiculoso, mediante plantio direto, com densidade de $8 \mathrm{~kg} / \mathrm{ha}$, com espaçamento de $17 \mathrm{~cm}$ entre linhas. No mesmo período, foi realizada roçada em toda área, permitindo-se o desenvolvimento do azevém de ressemeadura natural. Fez-se a adubação de base, a partir de análise do solo, conforme recomendação do Manual... (2004), para pastagens perenes de ciclo estival, sendo aplicados $60 \mathrm{~kg} / \mathrm{ha} /$ ano, tanto de $\mathrm{P}_{2} \mathrm{O}_{5}$ quanto de $\mathrm{K}_{2} \mathrm{O}$. Para a adubação nitrogenada, foram realizadas cinco aplicações, usando-se ureia, conforme cada tratamento, nos meses de outubro, novembro (2) e janeiro (2). Após a realização do $9^{\circ}$ pastejo, em fevereiro, foi observada a presença da cigarrinha das pastagens (Deois sp.). Para o seu controle, foi aplicado um produto biológico (METARRIL ${ }^{\circledR}$ - Pesticida biológico cujos ingredientes ativos são esporos do fungo Metarhiziumanisopliae). $\mathrm{Na}$ realização do 
pastejo seguinte, verificou-se baixa infestação, indicando a eficácia do produto no controle da cigarrinha.

O critério adotado para o início da utilização dos pastos, nas áreas com consórcio, em agosto, foi a altura - quando o trevo vesiculoso e a ervilhaca atingiram cerca de 30 e $40 \mathrm{~cm}$ de altura, respectivamente; para as áreas com cultivo singular, foi a altura do dossel do azevém (aproximadamente $25 \mathrm{~cm}$ ); a partir do sexto pastejo, em meados de dezembro, o critério foi a altura do dossel da Coastcross-1, próxima a $25 \mathrm{~cm}$. O método de pastejo utilizado foi o de lotação rotacionada, com um a dois dias de ocupação. A oferta de forragem real média foi de $5,3 \%$ do peso corporal.

Para avaliação, foram utilizadas vacas em lactação da raça Holandesa, de um plantel de 20 animais, com peso médio de $573 \mathrm{~kg}$ e produção média de 17,3kg de leite/dia. Após as ordenhas, as vacas receberam complementação alimentar, correspondente a $0,9 \%$ do peso corporal, à base de milho, soja e premix mineral, tendo à disposição sal mineralizado e água. Quando não estavam nas áreas experimentais, as vacas foram mantidas em pastagens da época. Antecedendo a entrada dos animais, foi estimada a massa de forragem, mediante técnica com dupla amostragem, adaptada de T'Mannetje (2000), efetuando-se cinco cortes feitos rente ao solo e 20 estimativas visuais, sendo repetida após a retirada dos animais dos piquetes para estimar a massa de forragem residual. A forragem das amostras cortadas foi pesada, sendo retirada uma subamostra para determinação das composições botânica e estrutural (para Coastcross-1). Esses componentes foram secos em estufa de ar forçado a $55^{\circ} \mathrm{C}$ até peso constante para determinação dos teores de matéria parcialmente seca, calculando-se, a seguir, a participação de cada componente.

Para a determinação do valor nutritivo da forragem, foram coletadas amostras pela técnica de pastejo simulado (Euclides et al., 1992), no início e no final de cada pastejo. As amostras foram pesadas, parcialmente secas em estufa com ar forçado a $55^{\circ} \mathrm{C}$, moídas em moinho do tipo "Willey" e acondicionadas na forma de amostra composta, misturando-se inicialmente as amostras de entrada e saída de cada piquete, do mesmo pastejo e, posteriormente, fez-se a mistura das amostras dos pastejos de acordo com a estação do ano. As amostras foram analisadas em laboratório quanto a proteína bruta, pelo método Kjeldahl (Association..., 1995), fibra em detergente neutro e fibra em detergente ácido (Van Soest et al., 1991), digestibilidade in situ da matéria orgânica e digestibilidade in situ da matéria seca (Mehrez e Orskov, 1977). A estimativa dos teores de nutrientes digestíveis totais foi obtida pelo produto entre a porcentagem de matéria orgânica (MO) e a DISMO dividido por 100 (Barber et al., 1984).

Para análise estatística, foram utilizados os dados médios dos pastejos conduzidos em cada estação do ano. $\mathrm{O}$ delineamento experimental utilizado foi o inteiramente casualizado, com três tratamentos (sistemas forrageiros), três repetições (piquetes) e parcelas subdividas no tempo (valores médios dos pastejos em cada estação do ano). Os resultados foram analisados valendo-se do procedimento MIXED, e a análise de variância, e as médias comparadas entre si pelo teste $\mathrm{F}$, em nível de $5 \%$ de probabilidade do erro, e quando significativo o efeito do sistema, foi submetido ao teste de Tukey para a comparação de médias. Foi utilizado o seguinte modelo estatístico: $\mathrm{Y}_{\mathrm{ijk}}=\mathrm{m}+\mathrm{T}_{\mathrm{i}}+\mathrm{R}_{\mathrm{j}}\left(\mathrm{T}_{\mathrm{i}}\right)+\mathrm{E}_{\mathrm{k}}+$ $(\mathrm{TE})_{\mathrm{ik}}+\varepsilon_{\mathrm{ijk}}$, em que: $\mathrm{Y}_{\mathrm{ijk}}$ representa as variáveis dependentes; $\mathrm{m}$ é a média de todas as observações; $\mathrm{T}_{\mathrm{i}}$ é o efeito dos tratamentos; $\mathrm{R}_{\mathrm{j}}\left(\mathrm{T}_{\mathrm{i}}\right)$ é o efeito de repetição dentro dos tratamentos (erro a); $E_{k}$ é o efeito das estações; (TE) $)_{\mathrm{ik}}$ representa a interação entre os tratamentos e estações; $\varepsilon_{i j k}$ é o efeito residual (erro b).

Comitê de Ética e Biossegurança: Protocolo 23081016073/2011-27, parecer 113/2011.

\section{RESULTADOS E DISCUSSÃO}

Durante o período de avaliação, da semeadura das leguminosas até o último pastejo (345 dias), foram conduzidos treze ciclos de pastejo, sendo dois no inverno, quatro na primavera, quatro no verão e três no outono, com tempo de ocupação de um a dois dias e intervalo médio entre pastejos de 25 dias. No inverno, a precipitação ficou abaixo das normais climatológicas, já na primavera os valores de precipitação obtidos ficaram acima das normais. No verão e no outono, as médias de precipitação ficaram próximas das normais. 
Quanto ao comportamento dos pastos, observa-se que a massa de forragem de pré-pastejo (Tab. 1), no inverno, foi constituída basicamente pelo azevém e leguminosas (nos respectivos consórcios), e nas demais estações pela Coastcross-1; no inverno, verificaram-se valores superiores $(\mathrm{P}<0,05)$ nos consórcios em relação à pastagem sem legumina; na primavera, houve similaridade e, nas demais estações, houve superioridade da pastagem que recebeu maior adubação nitrogenada em relação ao consórcio com trevo vesiculoso. No consórcio com ervilhaca, observa-se que a grande produção de massa dessa leguminosa implicou atraso no desenvolvimento das gramíneas acompanhantes (Grieu et al., 2001), tanto do azevém de ressemeadura natural quanto da Coastcross-1. Os valores de lâmina foliar de Coastcross-1 guardam proximidade entre os sistemas, havendo diferença apenas no inverno, com maior valor para o consórcio com trevo vesiculoso em relação à pastagem sem leguminosa. Nos consórcios, a participação da ervilhaca foi de $56,0 \%$ no inverno e $8,8 \%$ na primavera, e do trevo vesiculoso, de 17,$6 ; 17,3$ e $5,8 \%$ no inverno, primavera e verão, respectivamente.

Tabela 1. Massa de forragem, composição botânica e estrutural de pré-pastejo de diferentes sistemas forrageiros (SF), constituídos por Coastcross-1 + 100kg de N/ha/ano + ervilhaca (CE), Coastcross- $1+$ $100 \mathrm{~kg}$ de $\mathrm{N} / \mathrm{ha} / \mathrm{ano}+$ trevo vesiculoso (CT) e Coastcross- $1+200 \mathrm{~kg}$ de N/ha/ano (CN). Santa Maria, $2012 / 2013$

\begin{tabular}{|c|c|c|c|c|c|c|c|}
\hline \multirow{2}{*}{ Variável } & \multirow{2}{*}{$\mathrm{SF}$} & \multicolumn{4}{|c|}{ Estações } & \multirow{2}{*}{ Média } & \multirow{2}{*}{$\mathrm{CV}(\%)$} \\
\hline & & Inverno & Primavera & Verão & Outono & & \\
\hline \multicolumn{8}{|c|}{ Massa de forragem de pré-pastejo (Kg de MS/ha) } \\
\hline \multirow{6}{*}{ CV $(\%)$} & $\mathrm{CE}$ & $3061 \mathrm{Ab}$ & $3024 b$ & $4147 \mathrm{ABa}$ & $3948 \mathrm{ABa}$ & 3545 & 5,0 \\
\hline & $\mathrm{CT}$ & $2841 \mathrm{Ad}$ & $3199 \mathrm{c}$ & $3822 \mathrm{Ba}$ & $3542 \mathrm{Bb}$ & 3351 & 5,3 \\
\hline & $\mathrm{CN}$ & $2457 \mathrm{Bb}$ & $3264 b$ & 4739Aa & $4433 \mathrm{Aa}$ & 3721 & 4,8 \\
\hline & & 5,0 & 4,4 & 3,3 & 3,5 & & \\
\hline & \multicolumn{7}{|c|}{ Composição botânica (kg de MS/ha) } \\
\hline & $\mathrm{CE}$ & - & $966 \mathrm{~b}$ & $2374 \mathrm{a}$ & $1830 \mathrm{Bab}$ & 1293 & 15,6 \\
\hline \multirow[t]{2}{*}{$\mathrm{CC}$} & $\mathrm{CT}$ & $54 \mathrm{Bd}$ & $961 \mathrm{c}$ & $2357 \mathrm{a}$ & $1879 \mathrm{ABb}$ & 1313 & 15,4 \\
\hline & $\mathrm{CN}$ & $176 \mathrm{Ac}$ & $1245 b$ & $3296 a$ & $2777 \mathrm{Aa}$ & 1874 & 10,8 \\
\hline \multirow[t]{2}{*}{$\mathrm{CV}(\%)$} & & 17,8 & 7,4 & 8,1 & 10,0 & & \\
\hline & $\mathrm{CE}$ & $1173 \mathrm{~B}$ & $1232 \mathrm{~B}$ & - & - & 1202 & 9,5 \\
\hline \multirow[t]{2}{*}{ Azevém } & $\mathrm{CT}$ & $2136 \mathrm{Aa}$ & $1274 \mathrm{ABb}$ & - & - & 1705 & 6,7 \\
\hline & $\mathrm{CN}$ & $2075 \mathrm{Aa}$ & $1463 \mathrm{Ab}$ & - & - & 1769 & 6,4 \\
\hline CV $(\%)$ & & 5,2 & 7,0 & & & & \\
\hline \multirow{2}{*}{ Leguminosa } & $\mathrm{CE}$ & $1711 \mathrm{Aa}$ & $266 \mathrm{Bb}$ & - & - & 988 & 9,4 \\
\hline & $\mathrm{CT}$ & $501 \mathrm{Ba}$ & $553 \mathrm{Aa}$ & $222 b$ & - & 425 & 21,8 \\
\hline CV $(\%)$ & & 10,3 & 27,7 & & & & \\
\hline \multirow{3}{*}{$\begin{array}{l}\text { Outras } \\
\text { espécies }\end{array}$} & $\mathrm{CE}$ & $65 b$ & $286 \mathrm{ABb}$ & $1497 \mathrm{a}$ & $1758 \mathrm{a}$ & 902 & 9,7 \\
\hline & $\mathrm{CT}$ & $61 \mathrm{~b}$ & $187 \mathrm{Bb}$ & $980 \mathrm{a}$ & $1302 a$ & 632 & 13,8 \\
\hline & $\mathrm{CN}$ & $119 b$ & $310 \mathrm{Ab}$ & $1129 a$ & $1318 \mathrm{a}$ & 719 & 12,1 \\
\hline CV (\%) & & 20,6 & 10,0 & 14,4 & 6,8 & & \\
\hline \multirow{3}{*}{$\begin{array}{l}\text { Material } \\
\text { morto }\end{array}$} & $\mathrm{CE}$ & $112 b$ & $273 \mathrm{ab}$ & $276 a b$ & $360 \mathrm{a}$ & 255 & 10,0 \\
\hline & $\mathrm{CT}$ & $90 \mathrm{c}$ & $224 b$ & $263 a b$ & $360 \mathrm{a}$ & 234 & 10,9 \\
\hline & $\mathrm{CN}$ & $87 \mathrm{~b}$ & $247 a$ & $313 a$ & $338 \mathrm{a}$ & 246 & 10,4 \\
\hline \multirow[t]{2}{*}{ CV (\%) } & \multirow{2}{*}{\multicolumn{6}{|c|}{ 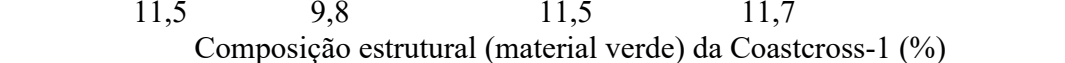 }} & \\
\hline & & & & & & & \\
\hline \multirow{3}{*}{$\begin{array}{l}\text {-Lâmina foliar } \\
\text { CC }\end{array}$} & $\mathrm{CE}$ & - & $48,7 \mathrm{a}$ & $40,7 \mathrm{~b}$ & $41,0 \mathrm{~b}$ & 43,5 & 2,4 \\
\hline & $\mathrm{CT}$ & $56,9 \mathrm{Aa}$ & $47,8 b$ & $41,1 \mathrm{c}$ & $37,9 \mathrm{c}$ & 45,9 & 2,2 \\
\hline & $\mathrm{CN}$ & $50,0 \mathrm{Ba}$ & $44,9 b$ & $40,1 \mathrm{c}$ & $41,0 \mathrm{bc}$ & 44,0 & 2,3 \\
\hline CV (\%) & & 2,2 & 2,5 & 2,9 & 3,0 & & \\
\hline \multirow{3}{*}{$\begin{array}{l}\text {-Colmo+ } \\
\text { bainha CC }\end{array}$} & $\mathrm{CE}$ & - & $51,3 \mathrm{~b}$ & $59,3 \mathrm{a}$ & $59,0 \mathrm{a}$ & 56,5 & 1,8 \\
\hline & $\mathrm{CT}$ & $43,1 \mathrm{Bc}$ & $52,2 \mathrm{~b}$ & $58,9 \mathrm{a}$ & $62,1 \mathrm{a}$ & 54,1 & 1,9 \\
\hline & $\mathrm{CN}$ & $50,0 \mathrm{Ac}$ & $55,1 \mathrm{~b}$ & $59,9 a$ & $59,0 \mathrm{ab}$ & 56,0 & 1,8 \\
\hline $\mathrm{CV}(\%)$ & & 2,6 & 2,2 & 2,0 & 2,0 & & \\
\hline
\end{tabular}

Médias seguidas por letras distintas, minúsculas na linha e maiúsculas na coluna, diferem entre si $(\mathrm{P}<0,05)$ pelo teste Tukey. $\mathrm{CC}=$ Coastcross $-1 . \mathrm{CV}=$ Coeficiente de variação. 
Quanto à presença de outras espécies (Paspalum conjugatum, papuã (Urochloa plantaginea), guanxuma (Sida santaremnensis) e paulistinha (Cynodon dactylon)), destaca-se que a participação foi expressiva nos diferentes sistemas, havendo tendência de aumento no decorrer do ano agrícola. Foram observadas diferenças entre os sistemas apenas na primavera, em que se observou superioridade do sistema sem leguminosa em comparação com o consórcio com trevo vesiculoso. Esse resultado deve-se, em parte, ao controle que as leguminosas exercem no sistema, reduzindo a presença dessas espécies (Sarrantonio, 1992). Barbero et al. (2009) obtiveram valores inferiores, de 7,51\%, avaliando na mesma época Coastcross-1 em consórcio ou não com amendoim forrageiro e com adubação nitrogenada de 0 a $200 \mathrm{~kg}$ de N/ha/ano.

Com relação ao material morto, não houve diferença entre os sistemas. Entre as estações, observa-se que os valores no inverno são menores, aumentando nas demais estações em função das perdas por pisoteio e do avanço do ciclo vegetativo da Coastcross-1, confirmado pela diminuição da participação de folhas em relação a colmos, especialmente no outono.

Para massa de forragem de pós-pastejo (Tab. 2) também ocorreram diferenças $(\mathrm{P}<0,05)$ entre os sistemas no inverno e no verão; houve similaridade na primavera e no outono. Essa diferença em relação à massa de pré-pastejo pode ser atribuída à presença das leguminosas nos pastos, pois a oferta foi a mesma para os três sistemas. Os dados da massa de forragem residual também demonstram que não houve limitações no consumo considerando a massa de forragem do azevém e das leguminosas (no inverno) e o valor de lâmina foliar da Coastcross1 (próximo a 30\%) para as demais estações. Segundo Paris et al. (2008), valores superiores a $30 \%$ de lâmina foliar implicam boa disponibilidade aos animais.

Quanto ao teor de proteína bruta das pastagens (Tab. 3), houve diferença $(\mathrm{P}<0,05)$ entre os sistemas forrageiros no inverno, sendo que o consórcio composto por Coastcross-1 e ervilhaca recebendo adubação nitrogenada de $100 \mathrm{~kg}$ de $\mathrm{N} /$ ha/ano foi superior aos demais. Esse resultado deve-se à grande participação dessa leguminosa no período (Tab. 1), o que resultou no aumento do teor de proteína bruta do sistema. Para o consórcio com trevo vesiculoso, o teor de proteína bruta foi mais baixo devido à menor participação $(17,6 \%)$ dessa leguminosa na pastagem. $\mathrm{O}$ valor obtido é similar ao encontrado por Rocha et al. (2003), de 20,8\% de proteína bruta, avaliando, no inverno, o consórcio de trevo vesiculoso com aveia preta e azevém com adubação de $150 \mathrm{~kg}$ de N/ha, em pastejo contínuo. O teor de proteína bruta do sistema sem leguminosa, no inverno, igualou-se ao do consórcio com trevo vesiculoso, devido à alta participação do azevém de ressemeadura natural (Tab. 1).

Para as demais estações não houve diferença entre os sistemas, havendo um declínio significativo no teor de proteína bruta devido à participação majoritária da Coastcross-1 e da maturação dessa gramínea no outono, condição esperada para as forrageiras de ciclo estival que normalmente apresentam menor valor nutritivo em relação às de ciclo hibernal (Olivo et al., 2007). O valor médio de proteína bruta obtido na primavera-verão (de 16,0\%) é similar ao observado por Alvim e Botrel (2001) na época das águas, de 17,6\%, em pastagens de Coastcross- 1 recebendo $100 \mathrm{~kg}$ de $\mathrm{N} / \mathrm{ha}$; o valor obtido no outono (de 14,2\%) se assemelha ao observado pelos mesmos autores na época da seca, de $12,9 \%$.

A menor variabilidade do teor de proteína bruta entre as estações foi obtida na pastagem sem leguminosa, resultado atribuído à maior disponibilidade de nitrogênio. Considerando-se o valor médio de proteína bruta dos sistemas (de $17,5 \%$ ), há similaridade com o teor obtido por Vilela et al. (2006), de 17\%, avaliando Coastcross- 1 em cultivo singular no decorrer de três anos agrícolas, utilizando adubação nitrogenada de $200 \mathrm{~kg} / \mathrm{ha}$, com irrigação. 
Tabela 2. Massa de forragem, composição botânica e estrutural de pós-pastejo de diferentes sistemas forrageiros (SF), constituídos por Coastcross- $1+100 \mathrm{~kg}$ de N/ha/ano + ervilhaca (CE), Coastcross- $1+$ $100 \mathrm{~kg}$ de N/ha/ano + trevo vesiculoso (CT) e Coastcross- $1+200 \mathrm{~kg}$ de N/ha/ano (CN). Santa Maria, $2012 / 2013$

\begin{tabular}{|c|c|c|c|c|c|c|c|}
\hline \multirow{2}{*}{ Variável } & \multirow{2}{*}{$\mathrm{SF}$} & \multicolumn{4}{|c|}{ Estações } & \multirow{2}{*}{ Média } & \multirow{2}{*}{$\mathrm{CV}(\%)$} \\
\hline & & Inverno & Primavera & Verão & Outono & & \\
\hline & \multicolumn{7}{|c|}{ Massa de forragem de pós-pastejo (Kg de MS/ha) } \\
\hline \multirow{6}{*}{ CV $(\%)$} & CE & $1653 \mathrm{ABb}$ & $1786 b$ & $2572 \mathrm{Aa}$ & $2434 \mathrm{a}$ & 2111 & 6,3 \\
\hline & $\mathrm{CT}$ & $1725 \mathrm{Ab}$ & $1714 b$ & $2244 \mathrm{Ba}$ & $2289 \mathrm{a}$ & 1993 & 6,7 \\
\hline & $\mathrm{CN}$ & $1351 \mathrm{Bb}$ & $1809 b$ & $2613 \mathrm{Aa}$ & $2783 \mathrm{a}$ & 2139 & 6,2 \\
\hline & & 4,7 & 3,7 & 2,3 & 6,5 & & \\
\hline & \multicolumn{7}{|c|}{ Composição botânica (kg de MS/ha) } \\
\hline & $\mathrm{CE}$ & - & 531 & 1143 & 982 & 664 & 12,7 \\
\hline \multirow[t]{2}{*}{$\mathrm{CC}$} & $\mathrm{CT}$ & $47 d$ & $469 c$ & $1220^{\mathrm{a}}$ & $852 b$ & 647 & 13,0 \\
\hline & $\mathrm{CN}$ & $84 \mathrm{c}$ & $587 \mathrm{~b}$ & $1546^{\mathrm{a}}$ & $1243 a$ & 865 & 9,7 \\
\hline \multirow[t]{2}{*}{$\mathrm{CV}(\%)$} & & 18,0 & 11,8 & 9,9 & 12,7 & & \\
\hline & $\mathrm{CE}$ & $937 \mathrm{Ba}$ & $631 b$ & - & - & 784 & 10,4 \\
\hline \multirow[t]{2}{*}{ Azevém } & $\mathrm{CT}$ & $1324 \mathrm{Aa}$ & $634 b$ & - & - & 979 & 8,4 \\
\hline & $\mathrm{CN}$ & $1115 \mathrm{ABa}$ & $666 b$ & - & - & 890 & 9,2 \\
\hline CV $(\%)$ & & 5,9 & 10,4 & & & & \\
\hline \multirow{2}{*}{ Leguminosa } & $\mathrm{CE}$ & $504 \mathrm{Aa}$ & $80 \mathrm{Bb}$ & - & - & 292 & 19,9 \\
\hline & $\mathrm{CT}$ & 149B & $178 \mathrm{a}$ & - & - & 163 & 29,9 \\
\hline CV (\%) & & 17,8 & 29,8 & & & & \\
\hline \multirow{3}{*}{$\begin{array}{l}\text { Outras } \\
\text { espécies }\end{array}$} & $\mathrm{CE}$ & $35 b$ & $212 b$ & $1096 \mathrm{a}$ & $1006 a$ & 587 & 9,4 \\
\hline & $\mathrm{CT}$ & $77 \mathrm{c}$ & $126 \mathrm{c}$ & $737 b$ & $980 \mathrm{a}$ & 480 & 11,5 \\
\hline & $\mathrm{CN}$ & $52 c$ & $217 \mathrm{c}$ & $715 b$ & $1125 \mathrm{a}$ & 527 & 10,5 \\
\hline CV (\%) & & 23,7 & 13,1 & 13,6 & 4,5 & & \\
\hline \multirow{3}{*}{$\begin{array}{l}\text { Material } \\
\text { morto }\end{array}$} & $\mathrm{CE}$ & $177 \mathrm{~b}$ & $331 \mathrm{ab}$ & $332 \mathrm{ab}$ & $446 a$ & 322 & 10,3 \\
\hline & $\mathrm{CT}$ & $130 \mathrm{c}$ & $309 b$ & $287 b$ & $457 \mathrm{a}$ & 296 & 11,2 \\
\hline & $\mathrm{CN}$ & $101 \mathrm{~b}$ & $339 a$ & $351 \mathrm{a}$ & $415 a$ & 302 & 11,0 \\
\hline \multirow[t]{2}{*}{ CV (\%) } & & 23,8 & 9,9 & 10,0 & 7,4 & & \\
\hline & \multicolumn{7}{|c|}{ Composição estrutural (material verde) da Coastcross-1 (\%) } \\
\hline \multirow{3}{*}{$\begin{array}{l}\text {-Lâmina } \\
\text { foliar CC }\end{array}$} & $\mathrm{CE}$ & - & $30,9 \mathrm{a}$ & $23,4 \mathrm{~b}$ & $28,5 \mathrm{ab}$ & 27,6 & 25,1 \\
\hline & $\mathrm{CT}$ & 41,0 & 27,8 & 26,0 & 27,6 & 30,6 & 22,7 \\
\hline & $\mathrm{CN}$ & $43,5 \mathrm{a}$ & $32,9 b$ & $22,0 \mathrm{c}$ & $25,7 \mathrm{bc}$ & 31,0 & 22,4 \\
\hline $\mathrm{CV}(\%)$ & & 4,2 & 19,4 & 24,9 & 22,2 & & \\
\hline \multirow{3}{*}{$\begin{array}{l}- \text { Colmo+ } \\
\text { bainha CC }\end{array}$} & $\mathrm{CE}$ & - & $69,1 b$ & $76,6 \mathrm{a}$ & $71,5 \mathrm{ab}$ & 72,4 & 9,6 \\
\hline & $\mathrm{CT}$ & 59,0 & 72,2 & 74,0 & 72,4 & 69,4 & 10,0 \\
\hline & $\mathrm{CN}$ & $56,5 \mathrm{c}$ & $67,1 b$ & $78,0 \mathrm{a}$ & $74,3 \mathrm{ab}$ & 69,0 & 10,1 \\
\hline CV (\%) & & 3,1 & 2,6 & 7,8 & 8,3 & & \\
\hline
\end{tabular}

Médias seguidas por letras distintas, minúsculas na linha e maiúsculas na coluna diferem entre $\operatorname{si}(\mathrm{P}<0,05)$ pelo teste Tukey. $\mathrm{CC}=$ Coastcross- $1 . \mathrm{CV}=$ Coeficiente de variação.

Quanto ao teor de FDN (Tab. 3), foram observadas diferenças $(\mathrm{P}<0,05)$ entre sistemas, no inverno, com valores superiores para o consórcio com trevo vesiculoso e para a pastagem sem leguminosa em relação ao consórcio com ervilhaca. Esse resultado deve-se à maior participação dessa leguminosa na composição da pastagem (Tab. 1). O valor elevado observado na pastagem sem leguminosa pode ser atribuído, em parte, à maior participação de Coastcross-1 na pastagem, que, como espécie de ciclo estival, apresenta, normalmente, teor mais elevado de FDN em relação às espécies de ciclo hibernal, como o azevém. Nas demais estações, não houve diferença entre os sistemas forrageiros. Para as pastagens em consórcio com leguminosas, os menores valores de FDN foram obtidos no inverno, havendo um aumento destes ao longo do ano. Esse aumento pode ser explicado pelo avanço do estágio de desenvolvimento das plantas com diminuição da proporção de folhas e 
aumento de colmos (Tab. 2) com consequente elevação dos teores de compostos estruturais, tais como celulose, hemicelulose e lignina, que compõem o FDN (Macedo Júnior et al., 2007).
Já o FDN da pastagem sem leguminosa apresentou menor variabilidade, diferindo apenas no inverno das demais estações.

Tabela 3. Valor nutritivo de diferentes sistemas forrageiros (SF), constituídos por Coastcross-1 $+100 \mathrm{~kg}$ de N/ha/ano + ervilhaca (CE), Coastcross-1 + 100kg de N/ha/ano + trevo vesiculoso (CT) e Coastcross-1 $+200 \mathrm{~kg} \mathrm{de} \mathrm{N} / \mathrm{ha} /$ ano $(\mathrm{CN})$. Santa Maria, 2012/2013

\begin{tabular}{|c|c|c|c|c|c|c|}
\hline \multirow{2}{*}{ SF } & \multicolumn{4}{|c|}{ Estações } & \multirow{2}{*}{ Média } & \multirow{2}{*}{ CV $(\%)$} \\
\hline & Inverno & Primavera & Verão & Outono & & \\
\hline & \multicolumn{6}{|c|}{ Proteína Bruta $(\%)$} \\
\hline $\mathrm{CE}$ & $27,5 \mathrm{Aa}$ & $16,3 b$ & $15,1 b c$ & $13,5 \mathrm{c}$ & 18,1 & 3,2 \\
\hline $\mathrm{CT}$ & $22,3 \mathrm{Ba}$ & $17,7 \mathrm{~b}$ & $13,1 \mathrm{c}$ & $13,8 \mathrm{c}$ & 16,7 & 3,5 \\
\hline $\mathrm{CN}$ & $21,9 \mathrm{Ba}$ & $17,2 \mathrm{~b}$ & $16,3 b$ & $15,2 b$ & 17,6 & 3,3 \\
\hline \multirow{2}{*}{ CV $(\%)$} & 2,8 & 3,9 & 4,5 & 4,7 & & \\
\hline & \multicolumn{6}{|c|}{ Fibra em detergente neutro $(\%)$} \\
\hline $\mathrm{CE}$ & $41,8 \mathrm{Bc}$ & $59,7 \mathrm{~b}$ & $63,4 \mathrm{ab}$ & $65,4 a$ & 57,8 & 2,1 \\
\hline $\mathrm{CT}$ & $47,9 \mathrm{Ac}$ & $58,6 \mathrm{~b}$ & $64,1 \mathrm{a}$ & $65,0 \mathrm{a}$ & 58,9 & 2,1 \\
\hline $\mathrm{CN}$ & $51,0 \mathrm{Ab}$ & $61,0 \mathrm{a}$ & $62,5 \mathrm{a}$ & $64,4 \mathrm{a}$ & 58,7 & 2,0 \\
\hline \multirow[t]{2}{*}{ CV $(\%)$} & 1,8 & 2,2 & 1,1 & 1,3 & & \\
\hline & \multicolumn{6}{|c|}{ Fibra em detergente ácido (\%) } \\
\hline $\mathrm{CE}$ & $22,3 b$ & $27,5 \mathrm{a}$ & $28,0 \mathrm{a}$ & $28,0 \mathrm{a}$ & 26,5 & 2,8 \\
\hline $\mathrm{CT}$ & $23,1 b$ & $27,7 \mathrm{a}$ & $27,2 \mathrm{a}$ & $28,3 \mathrm{a}$ & 26,5 & 2,8 \\
\hline $\mathrm{CN}$ & $24,4 \mathrm{~b}$ & $29,2 \mathrm{a}$ & $26,3 \mathrm{ab}$ & $27,1 \mathrm{ab}$ & 26,7 & 2,8 \\
\hline \multirow[t]{2}{*}{$\mathrm{CV}(\%)$} & 3,8 & 3,0 & 3,1 & 3,1 & & \\
\hline & \multicolumn{6}{|c|}{ Digestibilidade in vitro da matéria seca (\%) } \\
\hline $\mathrm{CE}$ & $86,9 \mathrm{a}$ & $77,5 \mathrm{bc}$ & $79,8 b$ & $74,1 \mathrm{Bc}$ & 79,6 & 3,6 \\
\hline $\mathrm{CT}$ & $86,7 \mathrm{a}$ & $76,3 b$ & $77,3 \mathrm{~b}$ & $75,4 \mathrm{ABb}$ & 78,9 & 3,6 \\
\hline $\mathrm{CN}$ & $86,7 \mathrm{a}$ & $77,8 \mathrm{~b}$ & $80,1 \mathrm{~b}$ & $77,7 \mathrm{Ab}$ & 80,6 & 3,6 \\
\hline \multirow[t]{2}{*}{$\mathrm{CV}(\%)$} & 1,6 & 2,4 & 1,9 & 3,1 & & \\
\hline & \multicolumn{6}{|c|}{ Digestibilidade in vitro da matéria orgânica (\%) } \\
\hline $\mathrm{CE}$ & $86,8 \mathrm{a}$ & $77,6 \mathrm{bc}$ & $80,6 b$ & $74,1 \mathrm{Bc}$ & 79,8 & 3,4 \\
\hline $\mathrm{CT}$ & $86,9 \mathrm{a}$ & $76,0 \mathrm{~b}$ & $78,0 \mathrm{~b}$ & $75,5 \mathrm{ABb}$ & 79,1 & 3,5 \\
\hline $\mathrm{CN}$ & $86,8 \mathrm{a}$ & $77,7 \mathrm{c}$ & $80,1 \mathrm{~b}$ & $77,9 \mathrm{Ac}$ & 80,6 & 3,4 \\
\hline \multirow[t]{2}{*}{$\mathrm{CV}(\%)$} & 1,5 & 2,4 & 1,8 & 3,1 & & \\
\hline & \multicolumn{6}{|c|}{ Nutrientes digestíveis totais $(\%)$} \\
\hline $\mathrm{CE}$ & $77,3 \mathrm{a}$ & $70,6 \mathrm{bc}$ & $73,1 \mathrm{ab}$ & $67,4 \mathrm{Bc}$ & 72,1 & 1,4 \\
\hline $\mathrm{CT}$ & $76,7 \mathrm{a}$ & $69,1 b$ & $71,0 \mathrm{~b}$ & $68,8 \mathrm{ABb}$ & 71,4 & 1,3 \\
\hline $\mathrm{CN}$ & $76,3 \mathrm{a}$ & $70,5 \mathrm{c}$ & $73,1 b$ & $71,1 \mathrm{Ac}$ & 72,7 & 1,4 \\
\hline $\mathrm{CV}(\%)$ & 1,1 & 1,3 & 1,2 & 1,3 & & \\
\hline
\end{tabular}

Médias seguidas por letras distintas, minúsculas na linha e maiúsculas na coluna, diferem entre si $(\mathrm{P}<0,05)$ pelo teste Tukey. CV = Coeficiente de variação.

Para a FDA, não houve diferença entre os sistemas; entre as estações, o valor médio no outono foi de $27,8 \%$ e para as demais, de $26,2 \%$, sendo similar ao observado por Branco et al. (2012), que, avaliando separadamente os componentes estruturais da Coastcross-1, no inverno, primavera e verão, obtiveram valor médio de 28,8\% de FDA para as lâminas de Coastcross-1. Já Prohmann et al. (2004) observaram FDA médio para a planta inteira (colmo, folha e material senescente) de
Coastcross- 1 , de $39,5 \%$, utilizando adubação de $140 \mathrm{~kg}$ de N/ha em pastejo contínuo com bovinos de corte; Bortolo et al. (2001) encontraram valores entre 43,6 e $57,8 \%$ de FDA, avaliando diferentes níveis de matéria seca residual em pastagem de Coastcross-1, com adubação de $200 \mathrm{~kg}$ de N/ha/ano. Segundo Van Soest (1994), a FDA é a que representa a parcela menos digestível da forragem, por isso é desejável que seu valor seja o mais baixo possível. 
Para a estimativa da DISMS, DISMO e NDT, houve diferença entre os sistemas somente no outono, com maior valor na pastagem sem leguminosa em relação ao consórcio com ervilhaca, não havendo diferença entre os consórcios. Esse resultado pode ser atribuído à maior disponibilidade de $\mathrm{N}$ de origem química, que é utilizado de forma mais rápida em relação ao $\mathrm{N}$ fixado pelas leguminosas de liberação mais lenta (Silva e Saliba, 2007). Comparando-se as estações, os valores mais elevados para essas variáveis, observados no inverno, devem-se à elevada participação do azevém de ressemeadura natural e leguminosas, nos respectivos consórcios, e à baixa contribuição do material morto e de outras espécies (Stobbs, 1973).

Considerando-se a média de DISMS nas estações da primavera, verão e outono, de $77,3 \%$, o valor é superior ao observado por Vilela et al. (2006), de $65,6 \%$, trabalhando com Coastcross-1 irrigada, em cultivo singular, recebendo adubação nitrogenada de $200 \mathrm{~kg}$ de N/ha. Para o NDT, o valor médio nesse período foi de $70,5 \%$, superior ao encontrado por Santos et al. (2008), de $63,6 \%$, trabalhando com Tifton 85 , com e sem irrigação, e recebendo $150 \mathrm{~kg}$ de N/ha.

\section{CONCLUSÕES}

O consórcio com ervilhaca colabora para a elevação do teor de proteína bruta e diminui o valor de fibra em detergente neutro da pastagem no inverno, porém sua grande participação, nessa estação, faz com que haja atraso no desenvolvimento inicial da Coastcross- 1 . O valor nutritivo de todos os sistemas forrageiros decaiu com o avanço do ciclo vegetativo da Coastcross1. A utilização dos consórcios de ervilhaca ou trevo vesiculoso com a Coastross-1 $+100 \mathrm{~kg}$ de $\mathrm{N} /$ ha/ano tem valor nutritivo equivalente à pastagem de Coastcross- $1+200 \mathrm{~kg}$ de N/ha/ano.

\section{REFERÊNCIAS}

ALVIM, M.J.; BOTREL, M.A. Efeitos de doses de nitrogênio na produção de leite de vacas em pastagem de coast-cross. Pesq. Agropec. Bras., v.36, p.577-583, 2001.

ASSOCIATION Official Analytical Chemists. Official methods of analysis. 16.ed. v.2. Washington: AOAC, 1995. 1015p.
BARBER, W.P.B.; ADAMSON, A.H.; ALTMAN, J.F.B. New methods of feed evaluation. In: HARESIGN, W.; COLE, D.J.A. (Eds.) Recent advances in animal nutrition. London: Butterworths, 1984. p.161- 176.

BARBERO, L.M.; CECATO, U.; LUGÃO, S.M.B. et al. Produção de forragem e componentes morfológicos em pastagem de coastcross consorciada com amendoim forrageiro. Rev. Bras. Zootec., v.38, p.788-795, 2009.

BORTOLO, M.; CECATO, U.; MARTINS, E.N. et al. Avaliação de uma pastagem de Coastcross (Cynodon dactylon (L.) Pers.) sob diferentes níveis de matéria seca residual. Rev. Bras. Zootec., v.30, p.627-635, 2001.

BRANCO, A.F.; VIANA, K.B.; CASTAÑEDA, R.D. et al. Chemical composition and crude protein fractions of Coastcross grass under grazing on winter, spring and summer in Southern Brazil. Acta Scient. Anim. Sci., v.34, p.183-187, 2012.

CORRÊA, L.A.; CANTARELLA, H.; PRIMAVESI, A.C. et al. Efeito de fontes e doses de nitrogênio na produção e qualidade da forragem de capim-coastcross. R. Bras. Zootec., v.36, p.763-772, 2007.

EUCLIDES, V.P.B.; MACEDO, M.C.M.; OLIVEIRA, M.P. Avaliação de diferentes métodos de amostragens sob pastejo. Rev. Bras. Zootec., v.21, p.691-702, 1992.

GRIEU, P.; LUCERO, D.W.; ARDIANI, R.; EHLERINGER, J.R. The mean depth of soil water uptake by two temperate grassland species over time subjected to mild soil water deficit and competitive association. Plant Soil, v.230, p.197209, 2001.

MACEDO JÚNIOR, G.L.; ZANINE, A.M.; BORGES, I; PÉREZ, J.R.O. Qualidade da fibra para a dieta de ruminantes. Cienc. Anim., v.17, p.7-17, 2007.

MEHREZ, A.Z.; ORSKOV, E.R.A study of the artificial fibre bag technique for determining the digestibility of feed in the rumen. J. Agr. Sci., v.88, p.645-650, 1977.

MANUAL de adubação e calagem para os estados do Rio Grande do Sul e Santa Catarina. Porto Alegre: SBCSNRS, 2004. 400p. 
MORENO, J.A. Clima do Rio Grande do Sul. Porto Alegre: Secretaria da Agricultura, 1961. $42 \mathrm{p}$.

OFFICIAL methods of analysis. 16.ed. Washington: AOAC, 1995. 2v, 1015p.

OLIVO, C.J.; CHARÃO, P.S.; PEREIRA, L.E.T. et al. Produtividade e valor nutritivo de pasto de capim-elefante manejado sob princípios agroecológicos. Rev. Bras. Zootec., v.36, p.17291735, 2007.

PARIS, W.; CECATO, U.; SANTOS, G.T. et al. Produção e qualidade de massa de forragem nos estratos da cultivar coastcross-1 consorciada com Arachis pintoi com e sem adubação nitrogenada. Acta Sci. Anim. Sci., v.30, p.135-143, 2008.

PROHMANN, P.E.F.; BRANCO, A.F.; JOBIM, C.C. et al. Suplementação de Bovinos em Pastagem de Coastcross (Cynodon dactylon (L.) Pers) no Verão. Rev. Bras. de Zootec., v.33, p.792-800, 2004.

ROCHA, M.G.; RESTLE, J.; FRIZZO, A. et al. Alternativas de utilização da pastagem hibernal para recria de bezerras de corte. Rev. Bras. Zootec., v.32, p.383-392, 2003.

SANTOS, N.L.; SILVA, M.W.R.; CHAVES, M.A. Efeito da irrigação suplementar sobre a produção dos capins tifton 85 , tanzânia e marandu no período de verão no sudoeste baiano. Cienc. Anim. Bras., v.9, p.911-922, 2008.

SARRANTONIO, M. Opportunities and challenges for the inclusion of soil-improving crops in vegetable production systems. HortScience, v.27, p.754-758, 1992.
SILVA, J.J.; SALIBA, E.O.S. Pastagens consorciadas: Uma alternativa para sistemas extensivos e orgânicos. Vet. e Zootec., v.14, p.818, 2007.

STRECK, E.V.; KÄMPF, N; DALMOLIN, R.S.D. et al. Solos do Rio Grande do Sul. 2.ed. Porto Alegre: EMATER/RS, 2008. 222p.

STOBBS, T.H. The effect of plant structure on the intake of tropical pasture. 2. Differences in sward structure, nutritive value, and bite size of animals grazing Setaria anceps and Chloris gayana at various stages of growth. J. Agr. Res., v.24, p.821-829, 1973.

T'MANNETJE, L. Measuring biomass of grassland vegetation. In: T'MANNETJE, L'.; JONES, R.M. Field and laboratory methods for grass land and animal production research. Cambridge: CABI, 2000. p.51-178.

VAN SOEST, P.J.; ROBERTSON, J.B.; LEWIS, B.A. Methods for dietary fiber, neutral detergent fiber, and no starch polysaccharides in relation to animal nutrition. J. Dairy Sci., v.74, p.35833597, 1991.

VAN SOEST, P.J. Nutritional ecology of the ruminant. Ithaca: Comstock, 1994. 479p.

VILELA, D.; LIMA, J.A.; RESENDE, J.C.; VERNEQUE, R.S. Desempenho de vacas da raça Holandesa em pastagem de Coastcross. Rev. Bras. Zootec., v.35, p.555-561, 2006. 